\title{
Students' Attitude Towards the Use of Information Communication Technology in College of Education, Ghana
}

\author{
Gershon Kofi Ladzekpo Alfred Doh Nukpetsi \\ Ada College of Education \\ P. O. Box AF 34, \\ Ada Foah-Ghana
}

\begin{abstract}
This study investigated students' attitude towards the use of ICT in the college of education in Ghana. This study was a triangulation mixed approach underpinned by pragmatic philosophical thought. It employed a descriptive survey and multiple case study designs, where data were collected in two phases using a questionnaire and a semistructured interview guide. At the quantitative phase, a questionnaire was administered to students while the qualitative phase involved semi-structured interviews for ICT tutors from the three colleges selected. The quantitative data were analysed and the results were presented using Independent sampled T-test, ANOVA, mean and Standard deviation. The qualitative data were thematically analysed to explain issues as they emerged from the quantitative data. The findings of the study revealed hypothesis 1 and 2 were all significant in terms of gender and colleges students' attitude towards the use of ICT in education. Contrary to the hypotheses, interviewee tutors asserted, although students are mostly present in the ICT centre and have a positive attitude towards ICT the usage of ICT information is mostly for their personal chatting with friends, and not for academic purposes.
\end{abstract}

Keywords: Students, Attitude, Information Communication Technology, College of Education and Tutors

DOI: $10.7176 / \mathrm{JEP} / 10-9-18$

Publication date:March $31^{\text {st }} 2019$

\subsection{Introduction}

Ghana as a developing country makes efforts to improve its educational system for national development. The implementation of Information and Communication Technology (ICT) was part of the strategy to help improve education in the country. Hence, it is expected that the proper and effective implementation of ICT would go a long way to bring about the desired results in our educational policy. The developmental goal can only be fully realised if education is equitable beyond mere enrollment or completion rates but to meet the Sustainable Development Goals (SDGs). It is therefore vital that nations focus on the quality of teaching and learning in the classroom throughout the education lifecycle (Global Monitoring Report, World Bank, 2015). To meet the SDGs through the power of education is a serious financial investment which is currently beyond the reach of developing country like Ghana but innovative solutions such as those offered by ICT can go a long way in bridging the gap (United Nations Educational, Scientific and Cultural Organization (UNESCO, 2014).

ICT is an existing and widely deployed technology that can be mobilized to step up the pace and scale of transformation in teaching and learning processes in higher education (Hanushek \& Woessmann, 2015). ICT can be a crucial enabler in helping to achieve the SDGs through higher education, particularly in developing countries like Ghana where closing the development gap requires substantial effort, innovation and investment (Ericsson Mobility Report, 2016). This has necessitated the intensive students' use of ICT in learning in colleges of education in order to broaden their understanding in their course areas. Introduction of ICT in colleges of education plays a role in shifting responsibility for learning from tutors to students and does not however remove the need for classroom leadership nor does it invalidate related traditional teacher skills and practices (Infodev, 2015) but students may have time to study or research a given topic on their own before it being taught in classroom.

Students' use of ICT applications is influenced by their attitudes towards research (Tondeur, Valcke, \& Van, 2008). Attitude is also important because of the fact that it is the controller of the actual behaviour of an individual, consciously and unconsciously. Hence, the attitude of students towards the attainment of a high-level knowledge is worthy of being examined through ICT education. Littlejohn (2002) described attitude as an accumulation of information about an object, person, and situation or experience, a disposition to act in a positive or negative way towards some objects. According to this theorist, attitudes towards any objects play an extremely important role in influencing subsequent behaviours towards it. Positive attitude towards ICT is critical if ICT is to be effectively integrated into the school curriculum.

There are still gaps to be filled as regards appropriate utilization of technology in the Ghanaian education system. As ICT has found its way into the education system of Ghana, students found in the colleges of education should not only provide an introduction and regular access to ICT but demonstrate its appropriate use. Notwithstanding, the belief that students are prepared for using ICT effectively in the classroom, a survey of ICT in education recently reported that most students still use ICT first and foremost to prepare their teaching and only a few use it during lessons for enhancing pedagogy (European Commission, 2013). Moreover, the attitude towards 
the use of ICT to enhance pedagogy and performance in the classroom is not clear. Busari (2003) found out that about half of the respondents in his study on computer use had the ability to use computers. ICT equipment is quickly evolving technologically making it difficult for students to make informed and different attitudes regarding which devices to use. Moreover, the rapidly evolving digital landscape results in challenges to determine students' attitude towards the use of ICT in teaching (Twining \& Henry, 2014).

Ghana has a variety of combinations of ICT tools available in colleges of education. Giving different ICT facilities in colleges, measuring students' attitude towards the use of the available ICT facilities is relevant as the need for Ghanaian pre-service teachers to be equipped with the use of ICT in relation to pedagogy and curriculum increases (UNESCO, 2011). However, ICT facilities in Ghana as a developing country are weak and this affects usage. Despite the existing teacher training, many simply do not use ICT during instruction due to a lack of experience, as well as the fact that many of the facilities have become obsolete (UNESCO-UIS, 2013). Students are thus ideally required to make informed decisions about which ICT tool to use and to ensure they have access to well-functioning devices which affects their attitude towards the usage of the facilities. These have revealed the low level of ICT penetration in the Ghanaian colleges of the education system, which affects the attitudes of students towards the usage. Therefore, there is a need to determine the attitudinal level of colleges of education students towards the use of ICT for instruction. Gaining an appreciation of colleges of education students' attitude in the use of ICT may provide useful insight into the future of technology usage in teaching and learning in colleges of education in Ghana. This paper, therefore, attempts to investigate students' attitude towards the use of information communication technology in the college of education in Ghana. The study made and tested the following hypotheses:

HO1: There is no significant difference between colleges with regard to students' attitudes towards the use of ICT in the College of Education in Ghana.

Ho2: There is no significant difference in gender towards the use of ICT in the College of Education in Ghana.

The present research is important for three reasons. First, this study will provide a general picture of the attitudes of students towards ICT and its use in colleges of education. Considering that attitudes have a strong connection to behaviour (Ajzen, 2005), it is possible to change students' behaviour toward using ICT in education once their attitudes are identified. Second, the findings of this study may help the Ministry of Education consider students' attitudes towards ICT as one of the influential factors in implementing the technology policy in the educational system. Knowledge of students' attitudes will surely help education decision-makers to design appropriate training for students. Necessary steps to change negative attitudes and/or foster positive ones may be needed to push the technological transformation in education forward. Third, it is hoped that the findings of this study would contribute to the existing body of knowledge and research about the integration of ICT into education in developing countries, many of which may have similar challenges and opportunities in the novelty of their technology initiatives. This study should provide valuable findings that other researchers could use as a guide to generate additional data on the topic in similar educational contexts.

\subsection{Constructivist Learning Theory}

The idea of integrating ICT into education is based on Constructivist Learning Theory that has been used to investigate the effect of the computer on teaching and learning. This learning theory is expected to help describe curriculum, a phenomena or an event and understand their relationship as well as to provide guidance for research and practice. Influenced by the progressive education movement, the Constructivist Learning Theory emphasizes the central role of learners in the curriculum and proposes that the curriculum be developed according to the learners' needs and interests (Gredler, 2000; Woolfolk, 2006). This theory promotes individual growth and makes the individuals (students) explore their potentials, discover and construct learning as well. Although theorists disagree about the definition of learning, most would agree that learning occurs when experience causes a permanent change in a person's knowledge or behaviour (Weiten, 2002). What is meant by "experience" in this definition refers to "the interaction of a person with his or her environment" (Woolfolk, 2006, p. 196).

In the 20th Century, the learning theories whose foundations and principles promoted a structured learning practice that teacher transmitted information and knowledge to students through such styles as lectures were the behaviorist and cognitive theories. Behaviorism and cognitivism did not value students' input and contribution to their own learning, so under these theories the students were passive participants in the learning process (Woolfolk, 2006). Unlike the behaviorist and cognitive theories that emphasized the important role of the teacher and the structured delivery of content, the constructivist theory emphasized the central role of students in the learning process and recognized the ability of students to construct meaning out of their learning (Kanuka \& Anderson, 1999).

Although the application of constructivist practices was touted in the latter half of the last century, theories that modeled student-centered learning existed easier. Constructivism as a learning theory has been influenced by the writings and thoughts of Piaget and Vygotsky (Woolfolk, 2006). Constructivist learning environments are structured in such a way that students are required to create meaning out of the context, and become actively 
involved in solving problems. Constructivism promotes interaction between students and their mentors, and this creates an environment where all students and mentors contribute to learning. Learning in a constructivist environment is constructed at different time, and thus there are no predetermined goals and structures to be followed (Gance, 2002). Generally, the following principles are derived from constructivism (Brooks \& Brooks 1999; Kanuka \& Anderson, 1999):

1. Learning is an active process in which the learner constructs meaning out of it.

2. Prior experience and knowledge are needed to learn new things.

3. People learn to learn as they learn. Learning consists of constructing both meaning and systems of meaning.

4. Motivation is critical to learning.

5. Experiencing learning is important for effective learning. Hands-on activities should be promoted.

\subsection{ICT and Constructivism}

Increased need for learning environments and practices that require interpersonal interaction, collaboration and opportunities to experience learning principles that constructivism promotes can be accomplished through the use of technology. Many educational institutions, especially at the post-secondary level, are promoting and adopting the integration of technology into teaching and learning. Reviewing McManus' (1996) work, Kanuka \& Anderson (1999) gave the example of using the Web for learning where learners use and explore the Web in different ways and from different directions, and small group discussions and presentations following the search lead to multiple interpretations of content and higher-order thinking.

According to Gance (2002), it is not always correct to assume that just because technology facilitates studentcentered learning, the constructivist strategies which are based on learners taking a central role in their learning are implemented. Most of the time, the use of software and the Web promote behaviours or practices that are not in line with the constructivist philosophy. For example, an online course geared towards individual learners, which does not promote collaboration or interaction and software program that is meant for drill and practice cannot be assumed to be applying the constructivist model.

\subsection{Role of Students}

ICT has changed the way students learn in schools. Students are no longer expected to learn specific sets of knowledge or skills. Unlike before, when content and subject matter were packaged for students, today's students have access to various tools (notably technology) for use in learning (Maier, et al., 1998). ICT empowers students by providing them with opportunities to solve problems. It enables students to share their skills and resources with their counterparts and teachers. ICT helps students to complete projects that would be difficult without it (Moursund, 1999). Students become involved in teaching and learning at the same time.

In a study on the use of ICT in a Science education class, Friedrichsen et al. (2001) found that students were motivated to contribute to the learning because of the computer simulations and online course management systems that were incorporated into the course. They stated that "the students moved from that of a science learner to a science teacher. In a mentored, small group setting, the students used the technology tools to support other students' scientific inquiry." (p. 385). The emergence of Web 2.0 with its social networking capabilities has opened up more possibilities for the advancement of teachers' and students' academic collaboration.

\subsection{Gender and ICT}

Many gender studies have been conducted over time to find the answer to the question of gender differences in ICT attitude and use (Bame, Dugger, deVries, \& McBee, 1993; Boser, Palmer, \& Daugherty, 1998; Meelissen, 2008 and Young, 1999). Most of the researchers in the early studies found that attitudes towards technology differed significantly between males and females, with male indicating greater interest and knowledge. With the exception of Liao (1999) who conducted a meta-analysis, all of the researchers investigating students' attitude and use of computers confirmed the widely accepted belief that males had a more positive attitude toward computers and used computers more than females did. Other researchers found that females perceived technology as more difficult and less interesting than males did (Boser, Palmer, \& Daugherty, 1998).

However, the difference in gender attitudes toward technology is not due to their biological construct but rather to their cultural and social construct. The attitude differences could be traced back to the placement and use of computers in education, where they were mainly used in research and administrative offices by white males (Linn, 1999). The differences may also have resulted from the dominant culture of males in technological fields; males use computer equipment more than females. (Hill, Loch, Straub, \& Elsheshai, 1998). In addition, the differences may be the direct impact of the technological environment at home. Many males and females perceived their homes as being more technological and rated both parents' occupations as more technical (Bame et al., 1993).

Other possible reasons for gender differences in terms of attitude toward and use of computers can be found in the following (Sharp, 2005): 
Most of the computer games are violent and appeal to the male population; computers are linked to Math and Science, fields that show an overrepresentation of males; magazines and newspapers depict men using the computer more than women; when women are associated with the computer, it is in a secretarial role; and many teachers encourage boys to use computers but discourage girls from doing so (p. 405).

Recent studies, however, show that gender attitudes toward computers are no longer significantly different. Female participants of a focus group conducted by the American Association of University Women Educational Foundation claimed that they like computers; they just use them differently than males (Bain \& Rice, 2006). As gender has an effect on attitudes, perceptions, and use of technology, it is important to understand gender differences in this regard.

\subsection{Research Methods}

The methodological choice of this study was underpinned by pragmatic paradigm but the design for the study was triangulation mixed method design (Creswell, 2014). The aim of the triangulation helps to explain more fully the richness and complexity of human behaviour by making use of both quantitative and qualitative data (Cohen, Manion, \& Morrison, 2007). Also, the combination of qualitative and quantitative approaches provides a more complete understanding of a research problem than either approach alone (Creswell, 2014). This approach requires the researcher to collect both quantitative and qualitative data simultaneously, and analyse them at the same time. Thus, in this approach, one set of data compliments the other, helping to overcome any weakness associated with each other (Creswell, 2014). Since the study is triangulation mixed method approach, the researcher intends to use descriptive survey design for the quantitative phase and multiple case study design for the qualitative phase.

The population for the study was all colleges of education students in Ghana. However, accessible population for the study comprised of all first year and second year students from Wesley College of Education, Kumasi; Komenda College of Education and Tamale College of Education. The sample consists of 1669 students. At the quantitative phase, census sampling was used to select 761 students from Wesley College of Education, Komenda College of Education 442 students and Tamale College of Education 446 while purposive sampling procedure was used to select three (3) ICT tutors from the three (3) selected colleges of education for the qualitative phase. A small sample was selected for the qualitative phase because Creswell, (2005) argued that selecting a large number of interviewees will 'result in superficial perspectives ... the overall ability of a researcher to provide an in-depth picture diminishes with the addition of each new individual or site' (p.207).

A structured questionnaire and a semi-structured interview were the instruments used to collect data for this study. The questionnaire was used to collect data for the quantitative stage, while the semi-structured interview guide was employed to gather data in the qualitative stage. By way to establish validity of the instruments, colleagues from the department of education were given the instruments check for flaws and problems in the study. Remarks from them were favourable and no changes were made in the instruments. The researchers checked reliability by asking the students to either confirm or disconfirm their statements after each interview have been transcribed. The data were analysed using Mean and Standard deviation, T-test and ANOVA (quantitative Phase) and thematic analysis was used for the qualitative phase. For example, Interviewee ICT Tutor from Wesley College of Education was assigned (IICTTWCoE-1); Interviewee ICT Tutor of Komenda College of Education (IICTTKCoE-2) and Interviewee ICT Tutor of Tamale College of Education (IICTTTCoE-3).

\subsection{Findings}

This section presents the findings of the study, related literature that was linked with findings to confirm or disconfirm the respondent's assertions. 
Table 1-Attitudes of Students towards ICT

\begin{tabular}{|c|c|c|c|c|}
\hline $\mathrm{S} / \mathrm{N}$ & Statement & $\mathrm{N}$ & $\mathrm{M}$ & SD \\
\hline 1. & I enjoy using my laptop my studies & 1669 & 3.15 & 0.79 \\
\hline 2. & $\begin{array}{l}\text { Working or studying with my laptop or } \\
\text { computer gives my control. }\end{array}$ & 1669 & 3.10 & 1.00 \\
\hline 3. & $\begin{array}{l}\text { ICT literacy is a necessity for my } \\
\text { academic work. }\end{array}$ & 1669 & 3.04 & 1.05 \\
\hline 4. & $\begin{array}{l}\text { It is easy to access and store data } \\
\text { through a computer. }\end{array}$ & 1669 & 3.00 & 1.03 \\
\hline 5. & $\begin{array}{l}\text { Using computer could provide me with } \\
\text { information that leads to better research } \\
\text { decision. }\end{array}$ & 1669 & 2.98 & 1.08 \\
\hline 6. & $\begin{array}{l}\text { Time spent at the ICT centre makes my } \\
\text { lesson more diverse. }\end{array}$ & 1669 & 3.19 & 0.89 \\
\hline 7. & $\begin{array}{l}\text { ICT gives me more confidence in } \\
\text { learning new concepts. }\end{array}$ & 1669 & 2.69 & 1.02 \\
\hline 8. & $\begin{array}{l}\text { Knowledge of ICT will facilitate the } \\
\text { fulfilment of my tasks. }\end{array}$ & 1669 & 2.87 & 0.95 \\
\hline 9. & Overall Mean and Standard Deviation & 1669 & 3.00 & 0.98 \\
\hline
\end{tabular}

Source: Field data (2018)

The overall mean and standard deviation score $(\mathrm{M}=3.00, \mathrm{SD}=0.98)$ gave evidence to prove that students have good attitude towards ICT in colleges of education in Ghana. The responses on the item "Time spent at the ICT center makes my lesson more diverse" recorded a mean of $3.19(\mathrm{SD}=0.89)$ which was within the highest score range. On issues of whether "I enjoy using their laptop or visit the ICT for their studies" a mean of 3.15 (SD=0.79) was recorded which shows that indeed students patronised the ICT center for the studies. On the contrary, IICTTKCoE-2 commented that,

"Although students visit and come for lectures during ICT education. I could see their interest is not in the training being given to them but free internet access which they can use in chatting on Facebook and posting pictures on Snap chat interest them more than researching on academic matters."

IICTTTCoE-3 added that "attending ICT lectures are compulsory to all students but their ability to transfer what is being learnt to other courses becomes the problem". The analysis further shows that working or studying with my laptop or computer gives my control recorded a mean score of 3.10 and a standard deviation of 1.00 . On how ICT literacy is a necessity for my academic work recorded $(\mathrm{M}=3.04, \mathrm{SD}=1.05)$ and easy to access and store data through a computer recorded a mean score of $3.00(\mathrm{SD}=1.03)$. IITTWCoE-1 said that "we made students believe that ICT training or knowledge in ICT education is core to their career attainment. Because students' positive attitude towards it will enhance their knowledge in research and in other course areas". Finally, all the results from Table 1 test value were more than 2.50. This shows an indication that students have good attitude toward ICT in colleges of education in Ghana.

\subsection{Research Hypothesis 1}

This section sought to find out the students' attitudes towards the use of ICT in College of Education. A One-way Analysis of Variance (ANOVA) was conducted to achieve the stated hypothesis.

Table 2-Summary of One-way Analysis of Variance (ANOVA)

\begin{tabular}{llllll}
\hline & $\begin{array}{l}\text { Sum of } \\
\text { Squares }\end{array}$ & df & $\begin{array}{c}\text { Mean } \\
\text { Squares }\end{array}$ & F & Sig \\
\hline $\begin{array}{l}\text { Between } \\
\text { Groups }\end{array}$ & 2795.68 & 2 & 1397.84 & 58.39 & .001 \\
$\begin{array}{l}\text { Within } \\
\text { Groups }\end{array}$ & 40116.43 & 1676 & 23.94 & \\
Total & 42912.11 & 1678 & & \\
\hline Source: Field data $(2018)$ & & $* *$ significant at $\mathrm{p}=0.05$ &
\end{tabular}

Table 2 shows that the overall $F$-ratio for the one-way ANOVA is significant. It noted that the $F$-ratio (58.39) is significant $(p=.001)$ at the .05 alpha level. This implies that there was a significant difference somewhere among the mean scores of the colleges in Ghana (Komenda College of Education, Wesley College of Education and Tamale College of Education). Based on this evidence, the researcher accepts the alternate hypothesis that states: 
"There is a significant difference between colleges in terms of attitude towards ICT education". However, the sig value of .001 did not tell the differences between the benefit levels among the colleges. The statistical significance of the differences between each pair of colleges is provided in multiple comparisons as indicated in Table 3 .

Table 3-Multiple Comparisons (The Post-Hoc Tests)

Dependent Variable: Attitudes towards ICT Education

\begin{tabular}{llcccc}
\multirow{2}{*}{ Colleges } & Colleges & Diff(I-J) & S $)$ & Mean & St.D \\
\hline Tamale & Wesley & $-2.93^{*}$ & .000 & 28.76 & 5.66 \\
& Komenda & $-3.22^{*}$ & .000 & & 4.90 \\
\multirow{2}{*}{ Kesley } & Tamale & $2.93^{*}$ & .000 & 31.69 & 4.35 \\
& Komenda & -0.30 & .514 & & \\
& Tamale & $3.22^{*}$ & .000 & 31.99 & \\
& Wesley & 0.30 & .514 & &
\end{tabular}

Source: Field data (2018)

** significant at $\mathrm{p}=0.05$

Table 3 shows the results of one-way between-groups analysis of variance conducted to check the colleges, as measured by the attitudes towards ICT education. Respondents were divided into three groups according to regions (Group 1 Tamale; Group 2 Wesley; Group 3 Komenda). There was a statistically significant difference at the $p<.05$ level in attitude towards ICT scores for the three colleges: $F(2,1676)=58.39, p=.001$. Post-hoc comparisons using the Tukey HSD test indicated that the mean score for Tamale College of Education $(\mathrm{M}=28.72$, $\mathrm{SD}=5.66)$ was significantly different from Komenda College of Education $(\mathrm{M}=31.99, \mathrm{SD}=4.35)$ and Wesley College of Education $(\mathrm{M}=31.69, \mathrm{SD}=4.90)$ but Komenda College of Education and Wesley College of Education do not differ significantly. Despite reaching statistical significance, the actual difference of the effect size in mean scores between the groups was not shown. The effect size was calculated using Eta squared formula:

Eta squared

$$
\begin{array}{r}
\left(\eta^{2}\right)=\frac{\text { Sum of squared between groups }}{\text { Total sum of squared }} \\
\left(\eta^{2}\right)=\frac{2795.68}{42912.11} \\
\left(\eta^{2}\right)=0.07
\end{array}
$$

In this example, the researcher divided the sum of squares for between-groups (2795.68) by the total sum of squares (42912.11). The result $\left(\eta^{2}\right)$ value is 0.07 has a moderate effect.

\subsection{Research Hypothesis 2}

An Independent-Sample T-test was conducted to achieve the stated hypothesis. This was done because two independent variables (gender) are measuring a dependent variable which is attitude toward the use of ICT.

Table 4-Group Statistic of Gender and ICT Use

\begin{tabular}{llccl}
\hline & Gender & $\mathrm{N}$ & Mean & St.D \\
\hline \multirow{2}{*}{ ICT Use } & Male & 805 & 31.39 & 4.73 \\
& Female & 864 & 29.76 & 6.43 \\
\hline
\end{tabular}

Source: Field data (2018)

Table 4 shows that the majority of the respondents $864(M=29.76, S D=6.43)$ were female as against $805(M=31.39$,

\begin{tabular}{|c|c|c|c|c|c|c|c|c|c|}
\hline & \multicolumn{3}{|c|}{$\begin{array}{l}\text { Levene's Test } \\
\text { For Equality } \\
\text { of Variance }\end{array}$} & \multicolumn{5}{|c|}{ T-test for Equality Means } \\
\hline & & $\mathrm{F}$ & Sig. & $\mathrm{t}$ & $\mathrm{df}$ & (2-tailed) & $\begin{array}{l}\text { Sig. } \\
\text { Diff }\end{array}$ & $\begin{array}{l}\text { Mean } \\
\text { Error }\end{array}$ & St.D \\
\hline Total & Equal & 93.50 & .00 & 10.78 & 1677 & .00 & & 1.63 & .34 \\
\hline Benefits & $\begin{array}{l}\text { Variance } \\
\text { Assumed } \\
\text { Equal variance } \\
\text { Not Assumed }\end{array}$ & & 12.88 & 309.34 & .00 & & & 1.63 & .42 \\
\hline
\end{tabular}
$\mathrm{SD}=4.73$ ) male that were in the minority.

Table 5-Independent Sample T-test for Gender and attitude toward ICT Use

An independent-sample T-test was conducted to compare the attitude toward ICT use scores for male and female. Table 5 shows sig. value 0.000 which was lesser than $p=0.05$, therefore, the data violate the assumption of equal variance. The equal variance was not assumed figures were used to interpret the findings.

There was significant difference in scores for male $(\mathrm{M}=31.39, \mathrm{SD}=4.73)$ and female $(\mathrm{M}=29.76, \mathrm{SD}=6.43 ; t$ $(309.34)=12.88, p=.05$, two-tailed). The magnitude of the differences in the means (mean difference $=1.63,95 \%$ 
confidence interval) was large with Eta squared $\left(\eta^{2}\right)$ value of 0.09 effect size. Based on the results, the alternate hypothesis stated as "There is a significant difference between gender and attitude towards the use of ICT in College of Education in Ghana" provided is accepted.

To arrive at the effect size, $\eta^{2}$ was used to calculate the difference. The Eta squared could aid the researchers to know the effect size of the magnitude difference between the schools. The procedure for calculating eta squared is provided below.

Replacing with the appropriate values from the formula above:

$$
\text { Eta squared }\left(\eta^{2}\right)=\frac{t^{2}}{t^{2}+(N 1+N 2-2)}
$$

$$
\eta^{2}=\frac{12.88^{2}}{12.88^{2}+(1421+258-2)}
$$

The magnitude of the differences in the means (mean difference $=1.63,95 \%$ confidence interval) was very large $\eta^{2}=0.09$.

\subsection{Discussion}

From the findings, it was reported that time spent at the ICT centre was helping students with their lesson. Others said that ICT literacy was a necessity or necessary for their academic. On the contrary, interviewees explained that students spent time at the ICT centre but time spent is mostly used on snap chat and Facebook or on other social media chat. Wheeler (1998) stated that by using the technology as a means to communicate with people, provide information, and offer a variety of services to the people, the government uses the ICT to update and improve its education system. Again, the study by Safar (2001) investigated the opinions and attitudes of students toward the use of computers and technology in K-12 education. Designed to find out value implementation for computer technology as an independent subject in K-12 schools versus integrating the computer in all other subjects, the research findings indicated that most of the participants had very positive attitudes toward the use of computer technology in education, supported the use of computer technology both as an independent discipline and as an integrated element with other subjects.

Hypothesis 1 shows that "There is a significant difference between colleges in terms of attitude towards ICT education". The alternate hypothesis was accepted. From the Post-hoc comparisons using the Tukey HSD test indicated that Tamale College of Education was significantly different from Komenda College of Education and Wesley College of Education but Komenda College of Education and Wesley College of Education do not differ significantly, where 0.07 moderate eta square value was recorded.

Independent Sample T-test was used to compute Hypothesis 2. The result shows that "There was a significant difference between gender and attitude towards the use of ICT in College of Education in Ghana". With respect to finding the actual difference eta square value of 0.09 was obtained which was very large. A study conducted by Olafare, Lawrence and Fakorede (2017), on colleges of education lecturers' attitude towards the use of information and communication technology in Nigeria, shows that the null hypothesis was accepted. By implication, the stated null hypothesis was established that there was no significant difference between colleges of education lecturers' attitude to the use of ICT based on gender.

\subsection{Conclusions and Recommendations}

Good attitude towards the use of ICT is important for colleges of education in Ghana. With effective use and training in ICT education would enhance their research. Poor attitude toward ICT usage may result in the lack of students' interest in research. Gura and Percy (2005) supported that ICT promises to redefine goals and methods of teaching and learning that are suitable for education in the 21 st Century. The promise, as the literature suggested, will not become a reality without teachers' understanding and positive attitude toward the technology, practical skills to use it, and their willingness to use the technology in actual classroom practice.

It recommends that institutions should set up internet access to students at all time and at all place within the school than just going to the ICT centre before they can access information. The availability of internet and ICT equipment could enhance students' interest in using ICT for their teaching and learning process.

\section{References}

Ajzen, I. (2005). Attitudes, personality, and behavior (2nd ed.). Milton-Keynes, England: Open University Press/McGraw-Hill.

Bain, C. D., \& Rice, M. L. (2006). The influence of Gender on attitudes, perceptions, and uses of technology. Journal of Research on Technology in Education, 39(2), 119-132.

Bame, A. E., Dugger, W. E. Jr., de Vries, M., \& McBee, J. (1993). Pupil's attitudes toward technologyPATT- USA. The Journal of Technology Studies, 19(1), 40-48. 
Boser, R. A., Palmer, J. D., \& Daugherty, M. K. (1998). Students' attitudes toward technology in selected technology education programs. Journal of Technology Education, 10(1), 4-18.

Brooks, J. G., \& Brooks, M. G. (1999). In search of understanding: The case for constructivist classrooms. Alexandria, VA: Association for Supervision and Curriculum Development.

Creswell, J. W. (2005). Educational research: Planning, conducting, and evaluating quantitative and qualitative research (3rd ed.). New Jersey: Pearson Education.

Creswell, J. W. (2014) Research design: Qualitative, quantitative, and mixed methods approaches (4 th ed.). Sage Publications, Inc., Thousand Oaks, CA.

Cohen, L., Manion, L., \& Morrison, K. (2007). Research methods in education (6th ed.). Madison Avenue, New York, NY: Routledge

Friedrichsen, P. M., Dana, T. M., Zembal-Saul, C., Munford, D., \& Tsur, C. (2001). Learning to teach with technology model: Implementations in secondary science teacher education. Journal of Computer in Mathematics and Science Teaching, 20(4), 377-394.

Gance, S. (2002). Are constructivism and computer-based learning environments incompatible? Journal of the Association of History and Computing. 5(1)

Gredler, M. (2000). Learning and instruction: Theory into practice. New York: Prentice-Hall.

Hill, C. E., Loch, C. K., Straub, D. W., \& El-Sheshai, K. (1998). A qualitative assessment of Arab culture and information technology transfer. Journal of Global Information Management, 6(3), 29-38.

Kanuka, H., \& Anderson, T. (1999). Using Constructivism in Technology-Mediated Learning: constructing order out of the chaos in the literature, In Radical Pedagogy, 1(2), 11.

Liao, Y. K. C. (1999). Gender differences on attitudes toward computers: A meta-analysis. Paper presented at the Society for Information Technology and Teacher Education International Conference, San Antonio, TX.

Linn, E. (1999). Gender equity and computer technology. Equity Coalition, 5, 14-17.

Maier, P., Barne, L., Warren, A., \& Brunner, D. (1998). Using technology in teaching and learning. London: Kogan Page Ltd.

Moursund, D. (1999). Project based learning using information technology. Eugene, OR: International Society for Technology in Education, 27(1).

Olafare, F. O., Lawrence, O. A., \& Fakorede S.O.A. (2017). Colleges of Education Lecturers Attitude Towards the Use of Information and Communication Technology in Nigeria. Malaysian Online Journal of Educational Sciences 5(4)1-12

Safar, H. A. (2001). Selective perspectives of implementing computer technology in K12 education in the state of Kuwait. (Doctoral dissertation, The University of Tennessee, 2002). Abstract from: ProQuest: Dissertation Abstract International, AAT 3022760.

Sharp, V. (2005). Computer education for teachers: Integrating technology into classroom teaching (5 ${ }^{\text {th }}$ Ed.).

New York: McGraw-Hill Companies, Inc

Weiten, W. (2002). Psychology: Themes \& variations $\left(5^{\text {th }}\right.$ Ed.). Belmont, CA: Wadsworth/Thomson.

Wheeler, D. (1998). Global culture or culture clash: New information technology in the Islamic world: A view from Kuwait. Communication Research, 25(4), 359-376.

Woolfolk, A. E. (2006). Educational psychology, (10 ${ }^{\text {th }}$ Ed.). Upper Saddle River, NJ: Allyn \& Bacon.

Young, B. J. (1999). Gender differences in student attitude toward computers. Journal of Research on Computing in Education, 33(2), 204-216. 